University of Wollongong

Research Online

Faculty of Social Sciences - Papers (Archive) Faculty of Arts, Social Sciences \& Humanities

$1-1-2019$

When a postgraduate student becomes a novice researcher and a supervisor becomes a mentor: A journey of research identity development

Melinda Kirk

University of Wollongong

Kylie Lipscombe

University of Wollongong, klipscom@uow.edu.au

Follow this and additional works at: https://ro.uow.edu.au/sspapers

Part of the Education Commons, and the Social and Behavioral Sciences Commons

Research Online is the open access institutional repository for the University of Wollongong. For further information contact the UOW Library: research-pubs@uow.edu.au 


\title{
When a postgraduate student becomes a novice researcher and a supervisor becomes a mentor: A journey of research identity development
}

\begin{abstract}
Developing a research identity is a critical space for novice researchers in teacher education. This coauthored self-study explores the experiences of a postgraduate Master of Education student who was working as a novice research assistant with her supervisor and how these experiences contributed to research identify development. Utilising Gee's (2000) Identity Framework as an analytical frame we, a novice researcher and supervisor, examine entries of a reflective research journal and supervisor feedback to gain insights into experiences that both support and constrain positive research identity development. Specifically, we promote mentorship and collaborative research as an effective strategy in normalising the typical feelings of vulnerability and self-doubt novice researchers experience but concede that challenges associated with power in-balances between student and supervisor are difficult to navigate. Recording the personal learning journey in the form of self study, serves to not only support self, but hopefully others endeavouring to begin research and those supervising postgraduate students in research projects. This is aligned with the assumption that self study should seek to facilitate research conversation, and not only provide links to literature but possibly add to the literature, whilst ultimately informing practice and development.
\end{abstract}

\section{Keywords}

postgraduate, student, becomes, novice, researcher, supervisor, mentor:, journey, identity, when, research, development

\section{Disciplines}

Education | Social and Behavioral Sciences

\section{Publication Details}

Kirk, M. \& Lipscombe, K. (2019). When a postgraduate student becomes a novice researcher and a supervisor becomes a mentor: A journey of research identity development. Studying Teacher Education, 15 (2), 179-197. 


\section{When a postgraduate student becomes a novice researcher and a supervisor becomes a mentor: A journey of research identity development.}

Developing a research identity is a critical space for novice researchers in teacher education. This co-authored self-study explores the experiences of a postgraduate Master of Education student who was working as a novice research assistant with her supervisor and how these experiences contributed to research identify development. Utilising Gee's (2000) Identity Framework as an analytical frame we, a novice researcher and supervisor, examine entries of a reflective research journal and supervisor feedback to gain insights into experiences that both support and constrain positive research identity development. Specifically, we promote mentorship and collaborative research as an effective strategy in normalising the typical feelings of vulnerability and self-doubt novice researchers experience but concede that challenges associated with power in-balances between student and supervisor are difficult to navigate. Recording the personal learning journey in the form of self study, serves to not only support self, but hopefully others endeavouring to begin research and those supervising postgraduate students in research projects. This is aligned with the assumption that self study should seek to facilitate research conversation, and not only provide links to literature but possibly add to the literature, whilst ultimately informing practice and development.

Keywords: research identity, novice researcher, mentoring, collaborative research

\section{Introduction}

The struggle to transition and develop professional competency and identity as a researcher and teacher educator is widely recognized in the literature (e.g. Allen, Park Rogers \& Borowski, 2016; McAnulty \& Cuenca, 2014). Recent attention has focussed on challenges for novice researchers. Feelings of isolation and limited support for becoming a researcher have been identified as significant factors that impact positive researcher development (Burrows, Thomas, Woods, Suess \& Dole, 2012; Chen, Wang \& 
Lee, 2016; Humphrey \& Simpson, 2013; Murphy, McGlynn-Stewart \& Ghafour, 2014). Consequently, universities have begun to develop greater opportunities for postgraduate and higher degree research students to research with more experienced researchers early on in their university studies and careers. Collaborative research and self study are adopted approaches, where students engage in research activities with experienced researchers to develop research capabilities while at the same time developing their research identities. This self study seeks to examine a novice researcher as a research assistant in her supervisor's research project and her own practices whilst reconciling common feelings associated with isolation and a lack of support (Dinkelman, Margolis \& Sikkenga, 2006; Harrison \& McKeon, 2010).

\section{Research context and background}

This paper reports on the experiences of XXX, a Master of Education student, referred to as a postgraduate student in Australia, as she collaborated as a research assistant in a research study with her supervisor while simultaneously completing a self study as part of a postgraduate teacher education program in Australia.

XXX was completing her final subject as part of a Master of Educational Leadership degree, which was a capstone research project. This project invites students to design and implement a small research project with the support of a supervisor over a five-month timeframe. The aim is to provide students with an opportunity to develop their professional growth by synthesising learning from their degree with prior learning and experiences in a student selected area requiring further investigation. For this reason, students often complete an action research project in their schools or a self study of their leadership development. XXX aspired to become a higher degree research student by continuing into a $\mathrm{PhD}$ program after completing her master degree. Hence, she sought to 
engage in self study as her capstone project. The focus of the self study was to examine and gain insights into her own knowledge and practices conducting research as a novice researcher. In discussions with her supervisor, $\mathrm{XXX}$ decided to become involved as a research assistant in her supervisor's research project while at the same time completing a self study to explore and develop a deep awareness of herself as novice researcher. In Australia, working as a research assistant in projects with a more experienced researcher is a common practice for postgraduate and higher degree researcher students to support the development of skills and experiences in academic research. As the literature asserts, understanding yourself as a researcher is integral to conducting effectual research, as the researcher knowledge assertions, values and processes directly influence research conducted (Cresswell, 2003; Glesne, 2006).

The research project $\mathrm{XXX}$ assisted in with her supervisor was a qualitative research study focussed on school and university partnerships. She assisted in data collection via semi-structured interviews with school leadership teams, co-reviewing the research literature, and observing and contributing to data analysis. $\mathrm{XXX}$ also copresented and co-authored a research paper to disseminate the findings of the study. While collaborating in the research project, $\mathrm{XXX}$ documented her experiences in research to examine her research identity and development in the form of her self study.

As XXX completed the self- study while simultaneously working as a research assistant, her supervisor took the deliberate approach to supervise through mentorship. Mentoring has been espoused by many authors as effective postgraduate supervision as it has the potential to facilitate a gradual development of research independency through conversations, modelling and collaboration (Manathunga, 2007; Pearson \& Brew, 2002; Price \& Money, 2002). Mentoring strategies included co-participating in data collection, modelling analysis techniques, leading reflective dialogue and providing both formal and 
informal feedback on research participation and writing. One tension of the nuanced supervision and mentoring role was the position of power. While some researchers argue that supervision, as a form of mentoring, involves "collaboration and interaction as collegial equals" (Wisker, 2012, p, 191), it was clear the notion of 'collegial equals' was not the case in this relationship. Clear institutional responsibilities bounded by evaluating the self study as a final capstone project resulted in a blurriness of roles between postgraduate student as novice researcher and supervisor as mentor. This relationship will be examined more closely in the findings and discussion.

In the next section we outline a conceptual and theoretical framework for this article by reviewing the relevant literature on research identity and mentoring and the theoretical framework to investigate research identity development of a novice researcher. Secondly, we provide the details of the self study that provides the empirical foundation for the exploration of research identity. Thirdly, the key findings related to the issues at hand are outlined. Finally, and importantly, we discuss the implications of the emerging findings for the development of research identity of a novice researcher and the implications associated with supervising and mentoring postgraduate students in this space.

\section{Research identity: A journey of challenge and self-doubt for novice researchers}

The sudden shift from teacher to researcher affords challenges and self-doubt recognised in the literature (Allen, Park Rogers \& Borowski, 2016; Murphy, McGlynn-Stewart \& Ghafour, 2014). Emotional support is required to navigate the new professional role of researcher. Chen, Wang and Lee (2016) suggest that emotional responses such as feelings of vulnerability are common for novice researchers. Furthermore, Kerdeman (2015) asserts that such emotions are 
necessary for developing self-understanding and it is the role of expert or mentor to facilitate self-questioning and self-understanding for novice researchers. It is advocated that openness to self-doubt enables learning and the consideration of multiple perspectives by, for example a mentor, is beneficial to developing professional competency (Kerdeman, 2015). Heightened self-awareness is considered essential for recognising the impact of researcher actions on others and beneficial to deep learning and identity development (Gee, 2000; Leibowitz, Ndebele \& Winberg, 2014).

Personal uncertainties and feelings of novice researcher vulnerability are compounded by a lack of research skills and experience to draw knowledge of processes and understanding (Murray \& Male, 2005). A lack of academic research experience contributes to anxiety and uncertainty regarding joining the scholarly conversation (Cotterall, 2015; Wellington, 2010). While it is recognized that it is through academic writing, contribution and publication that academic identity is realized (Reedy \& TaylorDunlop, 2015), this also adds to the pressure experienced by the novice researcher as they seek acceptance and recognition from other academics in the pursuit of an academic and research identity. Institutional factors such as limited support in developing research skills and experiences (Gallagher, Griffin, Parker, Kitchen \& Figg, 2011) and a lack of collaborative work environments (Harrison \& McKeon, 2008) make it difficult for novice researchers to develop positive efficacy to research and write on their own (Murphy, McGlynn-Stewart \& Ghafour, 2014).

While novice researchers face numerous challenges, collaboration and coauthorship opportunities within a research context are identified as positive developmental strategies (Chen, Wang \& Lee, 2016; Kamler \& Thompson, 2014; Leibowitz, Ndebele \& Winberg, 2014). Collaboration in the form of dialogue and 
participation in research with more experienced researchers has been shown to significantly develop positive research identities (Kamler \& Thompson, 2014). As such, collaborative research projects are an increasingly employed means of developing research identity as it provides a collaborative support platform (Leibowitz, Ndebele \& Winberg, 2014). Similarly, co-authorship with an experienced researcher is an increasingly recognized and adopted means to aid in supporting the transition of the novice researcher to academia (Lei \& Chuang, 2009).

The modelling of academic writing, co-researching and co-dissemination facilitates the recognition of novice research by others through resulting publication with an expert researcher (Lei \& Chuang, 2009; Reedy \& Taylor-Dunlop, 2015). Publication with experienced researchers is hence considered a social construct that is greatly beneficial to researcher identity development (Cotterall, 2015).

\section{Mentorship and novice researchers}

Mentorship has the potential to help research students and novice researchers grow and normalise into the profession (Boswell, Wilson, Stark \& Onwuegbuzie, 2015; FeimanNemser; 2001) and develop a researcher identity. Through on-going consultation and interaction, the mentor supports the novice researcher to become familiar with the expectations of scholarly research and writing while building their efficacy to collaborate and share research in a supportive environment (Lei \& Chuang, 2009). Cotterall (2011) champions an apprenticeship-like framework, under the guidance of a more experienced researcher, to aid the transition into academia and develop a positive identity as novice researcher. Opportunities for skill development through situated research and the building of a professional network are considered responsibilities of effective mentorship within this framework (Cotterall, 2011). 
The relationship between a more experienced researcher as mentor and a novice researcher as mentee is interactional and interdependent with both parties required to contribute to the effectiveness of the partnership (Zerzan, Hess, Schur, Phillips \& Rigotti, 2009). Literature commonly recognizes the role of mentor as significantly impacting the success of the mentor relationship through support and expert guidance (e.g., Palmer, Hunt, Neal \& Wuetherick, 2015; Zerzan, et al., 2009). Walkington (2005) believes that the role of mentee, however, is less understood but highly significant to mentoring success and must focus on active participation. Furthermore, it is recognized that mentee identification and sharing of learning gaps, needs, style and goals is integral to successful mentoring (Zerzan, et al., 2009). Kerdeman (2015) asserts that mentees' uncertainty and emotions are necessary for developing self-understanding and it is the role of the mentor to facilitate self-questioning for mentees as novice researchers. Heightened selfawareness is considered essential for recognizing the impact of researcher actions on others and beneficial to deep learning and identity development (Gee, 2000; Leibowitz, Ndebele \& Winberg, 2014).

\section{Framework of the self study}

The lens employed to frame this self study is Gee's (2000) Identity Framework. This frame was chosen as it identifies that self-perception and the perception of others is integral to the development of identity (Gee, 2000). Gee's Identity theory also provides an interactionist view that identity is a social product, shaped by self-image or perception, public image and the perception of how others view you (Charon, 2009; Fletcher \& Bullock, 2015; Jenkins, 2008). The components of this identity frame are not fixed or pre-determined, rather dynamic, interactive and contextually responsive (Gee, 2000). As such, it is a useful framework to explore and analyze the experiences of $\mathrm{XXX}$ as she 
participated as a research assistant in her supervisor's study. Table 1 outlines each of the viewpoints in the framework and how they are situated within XXX own viewpoints of self-identity. Following the table, each of these viewpoints are further elaborated.

TABLE 1: Gee's Four Viewpoints of Identity as a framework (Adapted from Gee, 2000, p100)

\begin{tabular}{|c|c|c|}
\hline Viewpoint & Description & Self study Identity \\
\hline NATURE-IDENTITY & $\begin{array}{l}\text { Developed from } \\
\text { forces in nature i.e. } \\
\text { "we are what- we are } \\
\text { primarily because of } \\
\text { our natures" }\end{array}$ & $\begin{array}{l}\text { Female } \\
\text { Middle aged } \\
\text { Mother }\end{array}$ \\
\hline INSTITUTION IDENTITY & $\begin{array}{l}\text { A position authorized } \\
\text { within institutions i.e. } \\
\text { "we are what we are } \\
\text { primarily because of } \\
\text { the positions we } \\
\text { occupy in society" }\end{array}$ & $\begin{array}{l}\text { Postgraduate student in a } \\
\text { Master of Education } \\
\text { degree (Australia) } \\
\text { Research assistant }\end{array}$ \\
\hline DISCOURSE IDENTITY & $\begin{array}{l}\text { How are we viewed } \\
\text { by others? Individual } \\
\text { traits recognized in } \\
\text { the discourse of/with } \\
\text { 'rational' dialogue } \\
\text { with others i.e." we }\end{array}$ & $\begin{array}{l}\text { Self-doubting } \\
\text { Nurturing }\end{array}$ \\
\hline
\end{tabular}




\begin{tabular}{|l|l|l|}
\hline & $\begin{array}{l}\text { are what we are } \\
\text { primarily because of } \\
\text { how we are } \\
\text { interactionally } \\
\text { recognized by others" }\end{array}$ & \\
\hline AFFINITY IDENTITY & $\begin{array}{l}\text { Experiences shared in } \\
\text { the practice of affinity }\end{array}$ & Teacher \\
groups i.e. "we are researcher & Research team member \\
what we are because & of the experiences we & \\
have had within & certain sorts of & \\
affinity groups" & \\
\hline
\end{tabular}

Initially, like other self study researchers (e.g. Allen, Park Rogers \& Borowski, 2016; Murphy, McGlynn-Stewart \& Ghafour, 2014) we did not include a novice researcher's $\mathrm{N}$-identity, that of a middle-aged female and mother. As an unalterable state, it was considered to have no consequence or bearing on this self study as it "remains constant and could not be influenced by the context or others" (Allen, Park, Rogers \& Borowski, 2016, p.8). However, through deep self-analysis and review of the following findings, this became an insight that will be examined and reported in the discussion. The duality of I-Identity, as a postgraduate teacher and research assistant was positioned within authorisation, that is, guidelines, timeframes, roles and responsibilities being both a student and research assistant. The third identity viewpoint, Discourse Identity (DIdentity), of being self-doubting, has been recognized by others and demonstrated through 
commonly received statements such as "stop doubting yourself" and "stop questioning yourself". An internal emphasis on others' views and concern of worthiness of interactionally recognized achievements overtime is recognized to perpetuate self-doubt, the identified D-Identity. Further, the viewpoint of "nurturing" as a second D-Identity is a recognized perception of others in both personal and professional contexts over time. Statements such as "you're caring" and "you're are such a mother hen" are examples of commonly received statements to XXX. While the third identify is how one is viewed by others, the fourth identity view, Affinity Identity (A-Identity), is focused on identity as a result of, or shaped through, participation in an 'affinity group'. Consequently, this self study considers the A-Identity as former teacher and developing A-Identity as a researcher and part of a research team, as critical insights in this self study. In the findings and discussion all four identity viewpoints are considered interactionally to gain a deeper understanding of influencing factors on developing a research identity.

\section{Research Questions}

A recognized challenge of self study is to develop questions that extend beyond our own questions to inform others (Zeichner, 2007). With this in mind, at the beginning of the self study, a research descriptor was developed in correlation with Glesne's (2006) advice for novice qualitative researchers to state the research focus with a one sentence descriptor, addressing the ostensible purpose and learnings of the research.

Through this self study influences on developing research identity, as a postgraduate student participating as a novice researcher conducting research with a supervisor within a mentorship model, is explored.

To approach this overarching research descriptor, three specific questions were then developed:

1. How does the postgraduate student feel about participating in research? 
2. What experiences contributed to research identity development?

3. How does mentorship contribute to research identity development?

\section{Data collection}

The need to be non-prescriptive and recognize the inconclusiveness inherent within self study was a significant consideration to data collection. Hence, reflectivity, the need to understand self and performance within the researcher role, is central to the self study (Hamilton, Smith \& Worthington, 2008; Postholm \& Skrøvset, 2015). As such multiple data sources were utilised to capture XXX's experiences as a postgraduate student during her role as research assistant.

Firstly, an autobiographical reflective journal was used to record events, observations, discussions, and to analyse and reflect on individual and collective experiences, learnings and how they may inform change (Cohen \& Manion, 2001; Cohen, Manion, Morrison, 2007). The journal was in paper form and used a similar structure advocated by Lamb (2013). The actual events, feelings and emotions associated with the events, learning points from the experience and evidence to substantiate the comments made, were included within journal entries (Lamb, 2013). Additionally, the reflective journal provided a tool for 'emotional recall' and reflection on research identity development (Ellis, 2004; Ellis \& Bochner, 2000; Nadin \& Cassell, 2006). Specifically, XXX attended to the research journal weekly, documenting events, activities and her associated experiences, feelings and learning. Both dot point entries and extended narratives were recorded. During intensive periods, such as when participating in data collection as a research assistant, more detail was included. The journal was a vehicle used by XXX to help document and develop research identity, whilst critically systematically analysing her own research practices and assumptions (Nadin \& Cassell, 2006). Table 2 shows a transcribed example of a journal entry informed by Lamb's (2013) 
journal entry structure. It highlights XXX's experiences and emotions and learning points associated with the research event of data analysis within her supervisor's researcher project.

TABLE 2: Journal notes from a data analysis event

\begin{tabular}{|l|l|l|}
\hline EVENT/EXPERIENCE & EMOTIONS & LEARNING POINTS \\
\hline Supervised, collaborative & UNSURE - I felt really & *Key findings we didn't \\
*Reviewed all recording & unsure today. It was my & expect have emerged. \\
interview data. & coding session and I wasn't & changing through analysis. \\
*Highlighted recurring & sure if I should just observe & I didn't realize this \\
words, terms \& phrases & or contribute. & occurred. \\
*Coded within key & VALUED - XXXX made & \\
research Questions \& & me feel really valued and & \\
Other & part of the research team by & \\
& asking my opinion. I & \\
\hline
\end{tabular}

As it is recognized that research journals can potentially lack objectivity by enabling a researcher to only focus on their own reflections, supervisor feedback provided secondary data sources for reliability and reflexivity (Hamilton, Smith \& Worthington, 2008). The recording of verbal and written feedback from the supervisor, in the form of email communications, completed surveys, recorded dialogues in meetings and formal written feedback on drafts provided a pivotal alternative perspective and data source. As an example, Table 3 shows an excerpt of transcribed supervisor feedback within formal review, normalizing XXX's feeling of uncertainty and self-doubt as a novice researcher. 
TABLE 3: Mentor feedback example

Excerpt from Mentor Review

XXX's confidence increased as she settled into the role. She lacked confidence in her literature review and was very unsure about her ability to complete this successfully however this is to be expected as a novice researcher...

\section{Data analysis}

Analysis of the data sources was coded, using Gee's Identity Framework (2000): Institutional Identity (I-Identity), Nature Identity (N-Identity), Discourse Identity (DIdentity) and Affinity Identity (A-Identity). Data was initially analysed by XXX using an open coding system of analysis. Firstly, data was coded deductively into three of Gee's (2000) viewpoints of identity. Using the journal entries and supervisors' feedback XXX's I-Identity (postgraduate student and research assistant), D-Identity (self-doubting and nurturing) and A-Identity (teacher, novice researcher, research team) were coded. However, as data was analysed it became apparent that N-Identity (middle aged mother, female) was in actual fact an important identity viewpoint which had important interconnections to research identity development. Originally $\mathrm{N}$-identity was thought of as a constant, not influenced by experiences or interactions and as such served no significance to research identity development. However, further analysis revealed that the four identities were interrelated and N-Identity was interactional with other identity viewpoints. As Gee (2000) suggests, an iterative process where intersections of XXX's four identity viewpoints were connected with other viewpoints (e.g., N-Identity and DIdentity) emerged within the data.

Together XXX and her supervisor, XXXX, examined the data coded within each of the viewpoints and searched for commonalities as emergent themes and saliences 
within each intersection. This triangulation between $\mathrm{XXX}$ and $\mathrm{XXXX}$ enhanced the trustworthiness and authenticity of data analysis (Cresswell, 2013) by reducing potential biases and selectivity. Significantly, through collaborative coding with Gee's (2000) Identity lens views, XXX's internalised self-doubt (D-Identity), emotions of self-doubt, were recognized as pivotal and an interactionally and interconnected consistent thread within the reflective journal and mentor feedback artefacts. Furthermore, the layering of Gee's ((2000) Identity coding with the three guiding questions, specifically regarding influencing experiences, emotions and mentorship was achieved through an analysis of commonly recurring words and key phrases. This coding process and the interconnectivity between Gee's (2000) identity lenses is demonstrated in an extract of coded data in Table 4.

TABLE 4: Coded Data

\begin{tabular}{|c|c|c|}
\hline Research questions & $\begin{array}{l}\text { Data from journal and } \\
\text { feedback }\end{array}$ & Coding (Gee, 2000) \\
\hline $\begin{array}{l}\text { How does the postgraduate } \\
\text { student feel about } \\
\text { participating in research? }\end{array}$ & $\begin{array}{l}\text { "I wondered how they would } \\
\text { view me" } \\
\text { "Remember you've got this, } \\
\text { you've done the research, you } \\
\text { know your stuff " } \\
\text { "I'm not sure how I can add to } \\
\text { the research" }\end{array}$ & D-Identity- self doubt \\
\hline $\begin{array}{l}\text { What experiences } \\
\text { contributed to research } \\
\text { identity development? }\end{array}$ & $\begin{array}{l}\text { "Well done with the } \\
\text { interview. The interviewees } \\
\text { said that they could relate to }\end{array}$ & A-Identity- teacher \\
\hline
\end{tabular}




\begin{tabular}{|l|l|l|}
\hline & $\begin{array}{l}\text { you and that you were easy to } \\
\text { talk to" } \\
\text { "I actually felt really good } \\
\text { whilst speaking, once I got }\end{array}$ & team member \\
\hline started" & A-Identity- research \\
\hline contribute to research & presentation together and & researcher, student \\
identity development? & practice. It will be great" & D-Identity- Self doubt \\
\hline
\end{tabular}

\section{Findings}

By conducting this self study, it is evident that our exploration of the role of a postgraduate student as novice researcher within a mentor model at a university, identified contributing factors to the development of research identity, but also barriers. Findings will be presented in consideration of each of the three research questions and inter-actively through the lens of Gees' (2000) identity framework. They will be reported on in first person by XXX as postgraduate student.

\section{How does the postgraduate student feel about participating in the research?}

Self-doubt, my D-Identity, was an overwhelming feeling I felt throughout the self study. Hence, by using my prior teaching experience (A-Identity), my middle-aged female and mother N-Identity, self memoing and supervisor feedback I sought to shift my overwhelming and negatively impacting feelings of self-doubt to more positive feeling of belonging and confidence. 
Overcoming self-doubt (D-Identity) through prior teacher experience (A-Identity):

Feelings associated with self-doubt were obvious throughout the entity of the study. Reflection statements such as "I don't know if this is good enough?" and email questions to my supervisor such as "Is this on the right track?" are exemplary of my ongoing selfdoubt and uncertainty. What became obvious, however, was that reconciling self-doubt was aided by connecting to my prior experience as a teacher. For example, the extract from my journal entry below, immediately after conducting semi-structured interviews with the principal and participants at the school being researched, shows how I desired not to be viewed as self-doubting by interviewees or within my role as researcher regardless of how I was feeling.

I had emailed the respondents prior to the interviews; however, I had never met them before. I think this added to why I felt really nervous...I've never conducted formal, recorded interviews before, and lacked a relationship with the two respondents. I wondered how they would view me and if they'd question why I was there conducting the research interviews.... They were incredibly busy, and as there had been a critical incident at the school today the Principal, was clearly pre-occupied. I really needed to build a relational trust, at some level, to be able to even commence the interview. I acknowledged that I really appreciated her time and that I understood schools are incredibly busy places and that she was dealing with a difficult incident...

As a research assistant, it is evident within this journal response that importance was placed on how others view me, a source of desired validation. Hence, to help me overcome my feelings I utilized my prior A-Identity of a teacher and experience and understanding of working in schools to demonstrate an appreciation for the participants in the study. This is exemplary of how, as a former teacher and current research assistant, I sought to establish a shared identity (A-identity) with teachers as well as researchers, enabling quality research, whilst building self-perception of worthiness to perform the 
research. This provided me with a source of confidence and diminished self-doubt, whilst building a sense of belonging within the new role of researcher.

Self-doubt associated with being nurturing (D-Identity) and N-Identity: My N-Identity as middle-aged female and mother and my self-perception of this, impacted my behaviours during the self study. This is exemplified in the following journal notes:

Wow- just listening to the recording, my voice is really soft and a bit slow even... I've often be told that I have a warm feminine voice and that I am nurturing, I can see why. I hope they didn't think I was weak or insecure though...

In this reflection I referred to my D-Identity, as nurturing, but self-questioned it as possibly problematic to my effectually conducting research interviews. On further deep analysis, this description of my voice and myself as nurturing, is identified as inter-related to my N-Identity, a force of nature as a middle aged, female and mother. While I viewed it as a possible constraint to my role as research assistant, my supervisors' written feedback based on my interviewing of participants, acknowledged my communication as "non-intimidating and professional". In further discussion about this written supervisor feedback and revealing how I felt, XXXX restated my voice as a positive "no I think it makes you approachable and non-intimidating, which is beneficial to interviewing and collecting data". This different analysis of the same data is indicative of how my supervisor's feedback helped me embrace my N-Identity and perceived interconnected D-Identity as nurturing and use it positively to affirm my actions and negate self-doubt.

Overcoming self-doubt (D-Identity) through self memoing: To moderate my potentially self-depreciating and self-limiting D-Identity, I wrote self-memos or survival memos throughout the research. The example, "You can do this!" is an example of my taking ownership of my behaviour and attempting to construct my own positive discourse, self- 
talk, to overcome feelings of vulnerability and self-doubt. The second example, "Remember you've got this, you've done the research, you know your stuff", is an example of a self-advice memo with validation from my supervisor, as it uses her positive oral feedback. The use of my supervisor's words encouraged me to overcome my selfdoubt and contribute to the research. It draws on my feelings of responsibility and need to fulfil my supervisor's expectations and validate her belief in my abilities, whilst adding credibility and believability in the statement and developing my A-Identity as a researcher.

Negating self-doubt (D-Identity) through supervisor feedback as an alternate perspective: Supervisor feedback was a significant mechanism for providing an alternative view to my self-doubt and ultimately shifting my D-Identity. This is recognized in the following reflection in my journal with consideration of verbal supervisor feedback, following my questioning of worthiness to conduct the research, as I positioned myself as a teacher not researcher.

When I explained to XXXX that I've only really taught before, and that I'm not sure how I can add to the research, XXXX was very reaffirming telling me it was natural to feel that way, and that my wealth of experience as a teacher, knowledge and understanding of how schools operate is an asset to draw on. She told me that it helps me to relate to participants and get the most out of interviews and data.

This is indicative of reaffirming feedback to negate self-doubt and encourage the acknowledgement and embracing of a new A-Identity as a researcher, whilst retaining and valuing my experiences and A-Identity as an experienced teacher.

\section{What experiences contributed to research identity development?}


The continuous engagement in academic reading and writing and the presentation of the research at a national conference were two important experiences that influenced by AIdentity as a novice researcher.

Developing understanding and belonging as a researcher (A-Identity) through academic reading and writing: Throughout this journey, I have immersed myself in the experience of academic reading. Whilst literature has been a source of learning and understanding, it has also been a challenge to bridge the nexus from reading and researching, to writing. For example, I discussed the need to move beyond reading in the following journal entry; I learned how to structure a literature review, through $\mathrm{XXXX}$ providing me with an example, discussing the structure, then doing it myself and receiving feedback. However, now I find myself reading and reading and reading, without writing....

This finding was supported by my supervisor who in dialogue said "you've done enough reading XXX, it's time to be writing. Don't question that you don't know enough. Share what you do know. Just back yourself...". On analysis, this tendency to only read, is indicative of me seeking to build my A-Identity as a researcher, through constructing shared understandings with scholarly writers and researchers, whilst enabling me to have the knowledge, confidence and self- perceived credibility to share my own perceptions and conceptions. To follow this feedback and to start writing required me to trust in my supervisor and myself and ultimately learn into my vulnerability. My growing readiness to do this is evident in the following journal entry.

Whilst reading Pinnegar and Hamilton (2015) Knowing, Becoming Doing as Teacher Educator, about intimate scholarship, I have had an 'aha' moment. Yes, I feel 'vulnerable' and it is my non-acknowledgement of this, or hiding from this, that is preventing me from sharing my final self study paper with XXXX and gaining the full benefit of her feedback. Pinnegar and Hamilton (2015) recognize that it is this 'vulnerability' that must be 
embraced, through honest self-analysis, to truly learn and develop a deep understanding and action 'intimate scholarship'. I must ultimately be prepared to lean into my vulnerability and share what I'm doing to learn.

Through academic reading and writing and then trusting myself, I was able to grow my awareness and acceptance of vulnerability as normal, as indicated within the above reflection. This prompted me to use and share my knowledge I acquired through reading and writing with my supervisor. This experience helped me become more comfortable in the space of researcher, where my A-Identity, as part of a research team was realized. My journal entry below shows how my experiences reading and then sharing my thoughts through writing helped me realise I have a responsibility to share my understanding as a member of a research team.

Remember to make sure that you write about what you read and what you did, how you felt and the outcomes straight away while it's fresh in your memory... also, it's okay to not feel certain, it's part of learning and developing as a researcher. Make sure you use it, review it and learn from it. This way you contribute all the new learning to the research team.

This demonstrates a shift in understanding of my A-Identity as a research team member and illustrates my self- management of negative feelings of self- doubt to contribute to the research project.

Growing into the role of novice researcher (A-Identity) through presentation: Throughout the self study, my confidence and competence as a novice researcher (AIdentity) were realised through the experience of presenting at the National Educational Leadership (ACEL) Conference in Australia. The following journal entry highlights how my initial feelings of self-doubt were shifted by presenting the research with my supervisor's feedback: 
I initially felt terrified. All the hard work and research came to fruition. I actually felt really good whilst speaking, once I got started... XXXX positive feedback after I practised in front of her really helped me through and gave me the boost I needed. She said that I needed to believe in what I know and have researched. She said that I'm an expert in lesson study as I've researched it thoroughly, and to believe in that. Just take a deep breath...

This statement is exemplary of supervisor feedback utilized to acknowledge my efforts and strength of research. Thus, developing my self-efficacy whilst aiding my acknowledgement of my I-Identity, of University authorised assistant researcher and building my sense of worthiness of my A-Identity as novice researcher.

\section{How does mentoring contribute to research identity development?}

Mentoring strategies were purposefully used by my supervisor to support my research development. The shift from supervisor to mentor was enabling of my A-Identity and DIdentity, however, the duality of the research assistant role and supervised postgraduate student also caused some challenges to research identity development.

A shift from supervision to mentorship: While XXXX was my formal supervisor, she appeared to be utilising mentoring strategies that provided more positive support rather than formal evaluative supervision. This was evident in the flexibility of deadlines, environment in which we collaborated, and development of a trusting relationship.

During my participation as research assistant I became sick. While as a postgraduate student this would normally require me to formally apply for an extension if deadlines could not be met, instead I was able to email XXXX, explain the circumstances and seek flexibility in meeting deadlines. This is evident in my journal, "I 
can't believe I'm sick... Thank-goodness XXX is understanding and has asked me when I will be able to complete the next research task rather than telling me".

Our collaborative space where we often met was also more inviting and comfortable than the typical office for supervision meetings. We regularly met at coffee shops or meeting spaces where we brought food and coffee to share while we worked. This environment enabled a more equal space to discuss ideas and concerns, co-problem solve and develop a positive relationship.

Furthermore, my supervisor demonstrated trust in my ability to collaborate and add value to the final resubmission of our paper, when she asked me to do the final edit. This is evidence in my journal entry below.

$\mathrm{XXXX}$ has asked me to be ruthless in the final edit of the paper, as we need to get the word count down. She said, just do what you think it needs, it's okay, you can be ruthless where you think it's needed... What a huge responsibility!

This is indicative of the shift in our interaction to a collaborative relationship, built on trust and mutual respect, enabled through my developing research identity (A-Identity) and growing efficacy, positively shifting D-Identity.

Challenges associated with the duality of research assistant and postgraduate student roles (I-Identity): Although mentoring strategies were a positive way to develop my research identity, the duality of my I-Identity, institutional positioning within this self study as research assistant, and as a supervised postgraduate student with research forming part of my final assessment for my degree was problematic. It provided a barrier to me fully and authentically engaging in communication and my A-Identity as part of a research team. The duality of this I-Identity resulted in behaviours that restricted true collaboration for learning and hesitancy for immersion in the assistant researcher role. This is thought to be a result of my fear of negatively impacting on my results, as my 
write up of my participation as research assistant, as a self study, was a part of a graded research project. My hesitancy to seek feedback and concern about negatively impacting on my postgraduate student identity (I-Identity) is demonstrated in the following reflection;

Although it is understood that constructive feedback is conducive to learning and development within supervision, at times I fear that revealing uncertainties, lack of progress or weaknesses could affect the way my work is viewed.

My avoidance to share progress and work in the form of writing is further evident and elaborated in the following reflection. This time, it is a fear of letting my supervisor down, that prevents me from sharing. This journal entry was at the culmination of the research and demonstrates a fear of inadequacy and losing my developing A-Identity as a researcher and part of the research team;

Although, XXXX, has always been supportive, provided constructive feedback and generally been an amazing supervisor, I find myself being reluctant to share my final self study paper with her? I keep delaying sharing with her for feedback. Why? I know her feedback will be beneficial and help me improve it, however I fear it's not worthy of sharing and I don't want to disappoint her.

The journal entry above is exemplified within email correspondence such as, "It's not ready to share yet, but working on it". This hesitancy to share was a result of waiting until mastery, and perceived worthiness before sharing. On deep analysis, this reluctance to share writing is now considered the result of immense feelings of vulnerability at the mere thought of the public sharing of my experiences and perceptions. Fear of not fulfilling my supervisor's expectations of me, her goal of developing my efficacy and research identity and not being worthy of a shared A-Identity as researcher was evident.

Whilst supportive supervision provided comfort and encouragement, the duality of my I-Identity Institutional positioning, as I am a postgraduate student at the university 
as well as conducting research collaboratively as a research assistant for my supervisor, provided hesitancy to perceive myself as a researcher. For example, when in discussion with an exhibitor at the National Conference we presented research at, I was asked what my role was, I replied "I'm the student to these two wonderful lecturers". This reply was renounced by my supervisor who responded, "you're more than a student, you're an experienced teacher and beginning researcher, you collaborated on the research with us". Through reflection, my supervisor's response acknowledged my Affinity Identity (AIdentity), as part of a research team, to help me substantiate and validate my own perception of worthiness of the role. The reference to my previous experience and prioridentity as an experienced teacher also served to aid my self-perception of worthiness within my new I-Identity, as an educational researcher, whilst constructing my A-identity, as a co-researcher. Significantly, this discourse is also indicative of a shift in positioning from supervision to mentorship and collaboration.

\section{Discussion}

Significantly, through this self study it is recognized that the transition from teacher to researcher is interactionally influenced and an ongoing process (Dinkelman, Margolis \& Sikkenga, 2006; Gee, 2000; Pinnegar \& Hamilton, 2015). Here, we discuss this transition and the importance of XXX A-Identity and N-identity in research identity development as well as the associated feelings of self-doubt and vulnerability during XXX's experiences and how she overcome them. We conclude with some insights into both the barriers and strengths of utilising mentoring to support postgraduate students working as novice researchers with their supervisors. While the findings were reported in first person by $\mathrm{XXX}$ as postgraduate student, the discussion will be reported by both authors. 
Initially, the A-Identity, as a previous teacher helped XXX substantiate and validate her own perception of worthiness of the role of researcher and participation in research. This draws attention to the importance of prior knowledge as teacher to the role of teacher researcher (Hamilton \& Pinnegar, 2015; Murray \& Male, 2005; Williams, Ritter \& Bullock, 2012). Accessing this prior experience and understanding to support and enable the new context of research was advantageous within this context. Whilst recognizing this prior identity as a source of knowledge and understanding or appreciation of education contexts, it is identified in the findings that a recognition of both A-Identities as a teacher and a researcher can enable quality research, as an understanding of both school and research perspectives is realized. Through this self study we concur that it is identified necessary for a novice researcher, such as $\mathrm{XXX}$, to resist the temptation to consistently cling to this prior identity, and the security it provides but instead use it to enable development within the new role of researcher (Allen, Park Rogers \& Borowski, 2016; Williams, Ritter \& Bullock, 2012).

While XXX's A-Identity as an experienced teacher provided a source of selfperceived worthiness, knowledge and confidence within the new role as researcher (Hamilton \& Pinnegar, 2015; Murray \& Male, 2005; Williams, Ritter \& Bullock, 2012), her N-Identity, as a middle-aged female and mother was identified inter-related with her nurturing (D-Identity), adding to her approachability and effectual interviews and research. Through this self study the honest acknowledging of self, behaviours and beliefs was understood to directly influence research conduct (Cresswell, 2003; Glesne, 2006).

As XXX shifted in her role from teacher to novice researcher, overwhelming feelings of self doubt (D-Identity) and vulnerability were raised. Although these feelings are not uncommon for novice researchers (Chen, Wang \& Lee, 2016), XXX's recognized D-Identity as being self-doubting compounded these feelings within this self-study. 
However, through the self study $\mathrm{XXX}$ recognized that she could reconcile her negative D- Identity by taking ownership of her own participation within the research (Walkington, 2005) and mentorship with her supervisor (Zerzan, et al., 2009). As Gee’s (2000) identity framework acknowledges, identity is not a fixed state but dynamic and alterable (Gee, 2000). Hence, Survival Advice Memo’s (Cohen, Manion, Morrison, 2007) were adopted by XXX to self-manage overwhelming feelings of vulnerability, develop research efficacy and consequently positively shift her D-Identity. Additionally, engagement in academic reading proved a source of knowledge and understanding, required to overcome the fear of uncertainty, and lack of skills and knowledge to conduct effectual research (Kwan, 2008), join the scholarly conversation (Wellington, 2010; Cotterall, 2015) and be viewed as a researcher. However, the journey from reader to writer was considered challenging (Kwan, 2008; Kamler \& Thompson, 2014). Whilst literature served to inform self-adjustments for $\mathrm{XXX}$, it was also identified as an ongoing challenge to bridge the nexus from reading and researching to writing (Kwan, 2008) as reading provided a place to hide.

The reluctance for XXX to write and share with her supervisor may also be the result of vulnerability and the informal evolving relationship between supervisor as mentor. The duality of roles as a supervised postgraduate student collaboratively conducting research with a supervisor as mentor, provided significant challenges and a barrier to XXX's authentic participation and revelation of deficits and concerns within this self study. In teacher education and postgraduate studies, it is recognized that the mentorship structure itself can serve to hinder mentee participation and collaboration (Zerzan, et al., 2009). Moreover, within this self study, XXX's vulnerability was further compounded by the duality of the mentor role being that of a superior and ultimately responsible for the evaluation of the mentee's achievements. Vulnerability and self-doubt 
(D-Identity) as well as mentorship situated within a supervisory role hence can be a barrier to true collaboration.

In consideration of barriers associated with vulnerability, self-doubt and supervisor-mentor relationships, a positive relationship built on trust and acceptance of vulnerability and collaboration between XXX and XXXX ultimately enabled successful outcomes (LaBoskey, 2004; Samaras, 2011; Mena \& Russell, 2017). This was achieved through an emotionally supportive structure (Lei \& Chuang, 2009). The reframing of selfdoubt as necessary and encouraging deliberate, constructive self-questioning and reflection, within a support structure, was conducive to developing $\mathrm{XXX}$ 's research identity within this self study. Ultimately, the normalising of vulnerability and extending beyond what is comfortable was emotionally supported through positive affirmation, alignment and guidance from XXXX as supervisor (Reedy \& Taylor-Dunlop, 2015) and enabled a shift from postgraduate student to novice researcher and supervisor to mentor.

\section{Concluding thoughts}

A final note to conclude this paper is the outcome of this novice researcher and mentor relationship beyond the self study. A continuation of mentorship and a collaborative research partnership, beyond graduation even though $\mathrm{XXX}$ has moved interstate, is a significant outcome of this self study and mentorship. This development is consequential of mentorship beyond supervision, a supportive apprenticeship-like model of mentorship (Cotterall, 2011).

Through the opportunity of a mentored relationship, the development of researcher understanding has been optimised, the sharing of research enabled, and efficacy fostered. Enhanced research capacity, scholarly writing efficacy, and positive research identity development has been promoted (Kamler \& Thomson, 2007; Larcombe, McCosker \& 
O’Loughlin, 2007; Murphy, McGlynn-Stewart \& Ghafour, 2014). A sense of vulnerability, with the principle of honest self-analysis and critique, enabled authentic learning, self-understanding and researcher identity development (Hamilton \& Pinnegar, 2015; Hamilton \& Pinnegar, 2015b; Pinnegar \& Hamilton, 2009; Pinnegar, Hamilton \& Fitzgerald, 2010). Furthermore, this mentorship and self study has enabled XXX's efficacy and positive research identity to further pursue education research. This is evidenced as she is now employed as a research assistant for a major education research project at an Australian University. Resultantly XXX's development of a positive research identity and efficacy to contribute to the field has been realised.

The implications of this work add to the growing conversation around the use of self study, collaborative research and mentoring to develop research identity for novice researchers. However, it is acknowledged that the study was limiting in that the mentor's perceptions were not explored. This raises the question about how collaboration between novice and more experienced researcher may enable or challenge research identity development for experienced researchers. Future research in the area of research identity of experienced researchers through the facilitation of collaborative research and mentoring is required. Through this self study however, we champion mentorship of postgraduate students in teacher education and hope that the sharing of this personal journey of research identity growth, of a novice researcher, may stimulate conversation and serve to support the preparation of fellow novice researchers and mentors.

\section{Disclosure Statement}

The authors reported no potential conflict of interest. 


\section{References}

Allen, J., Park Rogers, M. \& Borowski, R. (2016). “I am Out of My Comfort Zone”: Self-study of the Struggle of Adapting to the Professional Identity of a Teacher Educator. Studying Teacher Education, 12(3), 320-332.

Boswell, J.N., Wilson, A.D., Stark, M.D. \& Onwuegbuzie, A.J. (2015). The role of mentoring relationships in counselling programs. International Journal of Mentoring and Coaching in Education, 4 (3), 168 - 183.

Burrows, A., Thomas, J., Woods, A., Suess, R. \& Dole, D. (2012). Riding the wave: student researcher reflection on the action research process. Educational Action Research, 20(2), 291-312.

Charon, J.M., (2009). Symbolic interactionism: an introduction, an interpretation, an Integration (10th ed.). Upper Saddle River, NJ: Prentice Hall.

Chen, D., Wang, Y. \& Lee, W. (2016). Challenges confronting beginning researchers in conducting literature reviews. Studies in Continuing Education, 38(1), 47-60.

Cohen, L., \& Manion, L. (2001). Research Methods in Education. New York, NY: Routledge.

Cohen, L., Manion, L., \& Morrison, K. (2007). Research Methods in Education (6 ${ }^{\text {th }}$ ed.) .London, UK: Routledge Taylor \& Francis.

Cotterall, S. (2011). Doctoral students writing: where's the pedagogy. Teaching in Higher Education, 16(4), 413-425.

Cotterall, S. (2015). The rich get richer: international doctoral candidates and scholarly Identity. Innovations in Education and Teaching International, 52(4), 360-370.

Creswell, J. W. (2003). Research design: Qualitative, quantitative, and mixed methods approaches (2nd. ed.). Thousand Oaks CA: Sage. 
Dinkelman, T., Margolis, J., \& Sikkenga, K. (2006). From teacher to teacher educator: experiences, expectations, and expatriation. Studying Teacher Education, 2(1), 524.

Ellis, C. (2004). The ethnographic I. Walnut Creek, CA: Altamira Press.

Ellis, C., \& Bochner, A. (2000). Autoethnography, personal narrative, reflexivity. In N. Denzin \& Y. Lincoln (Eds.), Handbook of qualitative research (2nd ed., pp. 733-768). Thousand Oaks, CA: Sage.

Feiman-Nemser, S. (2001). From preparation to practice: Designing a continuum to strengthen and sustain teaching. Teachers College Record, 103, 1013-1055.

Fletcher, T. \& Bullock, S. M. (2015). Reframing pedagogy while teaching about teaching online: a collaborative self-study. Professional Development in Education, 41(4), 690-706.

Gallagher, T., Griffin, S., Parker, D. C., Kitchen, J., \& Figg, C. (2011). Establishing and Sustaining Teacher Educator Professional Development in a Self-Study for Peer Review Only Community of Practice: Pre-Tenure Teacher Educators Developing Professionally. Teaching and Teacher Education: An International Journal Of Research and Studies, 27(5), 880-890.

Gee, J. P. (2000). Identity as an analytic lens for research in education. Review of Research in Education, 99-125.

Glesne, C. (2006). Becoming qualitative researchers: An introduction (3rd ed.). Boston, Pearson, Allyn \& Bacon.

Hamilton, M. L., Smith, L., \& Worthington, K. (2008). Fitting the methodology with the research: An exploration of narrative, self-study and auto-ethnography. Studying Teacher Education: A Journal of Self-Study of Teacher Education Practices, 4, 17-28. 
Hamilton, M. L., \& Pinnegar, S. (2015). Disruption - Forming, Framing, and Linking in Developing Research Questions. Advances in Research on Teaching, 26, 303317.

Hamilton, M. L., \& Pinnegar, S. E. (2015b). Knowing, becoming, doing as teacher educators: identity, intimate scholarship, inquiry. Bingley, England: Emerald.

Harrison, J., \& McKeon, F. (2010). Perceptions of beginning teacher educators of their development in research and scholarship: Identifying the "turning point" experiences. Journal of Education for Teaching, 36, 19-34.

Humphrey, R., \& Simpson, B. (2013). Negotiating a 'scary gap': Doctoral candidates, 'writing up' qualitative data and the contemporary supervisory relationship. Journal of Education and Training Studies, 1, 1-10.

Jenkins, R. (2008). Social identity (3rd ed.). London: Routledge.

Kamler, B., \& Thomson, P. (2004). Driven to Abstraction: Doctoral Supervision and Writing Pedagogies. Teaching in Higher Education, 9(2), 195-209.

Kamler, B. \& Thomson, P. (2014). Helping Doctoral Students Write: Pedagogies for Supervision (2nd ed.). London, UK: Routledge.

Kerdeman, D. (2015). Preparing Educational Researchers: The Role of Self-Doubt. Educational Theory, 65(6), 719-738.

Kwan, B.S.C. (2008). The nexus of reading, writing and researching in the doctoral undertaking of humanities and social sciences: Implications for literature reviewing. English for Specific Purposes, 27, 42-56.

LaBoskey, V.K. (2004). The methodology of self-study and its theoretical underpinnings. In J.J. Loughran. M.L. Hamilton, V.K. LaBoskey., \& T. Russell (Eds.), International Handbook of Self-Study of Teaching and Teacher Education practices (pp. 817-869). Dordrecht, The Netherlands: Kluwer Academic. 
Lamb, D. (2013). Promoting the case for Using a Research Journal to Document and Reflect on the Research Experience. The Electronic Journal of Business Research Methods, 11(2), 84-91.

Larcombe, W., McCosker, A., \& O’Loughlin, K. (2007). Supporting education PhD and DEd students to become confident academic writers: An evaluation of thesis writers' circles. Journal of University Teaching and Learning Practice, 4, 54-63.

Lei, S. A., \& Chuang, N. (2009). Research Collaboration and Publication During Graduate Studies: Evaluating Benefits and Costs from Students' Perspectives. College Student Journal, 43(4), 1163-1168.

Leibowitz, B., Ndebele, C., \& Winberg, C. (2014). 'It's an amazing learning curve to be part of the project': exploring academic identity in collaborative research. Studies in Higher Education, 39(7), 1256-1269.

McAnulty, J., \& Cuenca, A. (2014). Embracing institutional authority: The emerging identity of a novice teacher educator. Studying Teacher Education, 10, 36-52.

Manathunga, C. (2007). Supervision as mentoring: the role of power and boundary crossing. Studies in Continuing Education. 29 (2), 207-221.

Mantzoukas, S. (2008). Facilitating research students in formulating qualitative research questions. Nurse Education Today, 28(3), 371-377.

Mena, J., \& Russell, T. (2017). Collaboration, Multiple Methods, Trustworthiness: Issues Arising from the 2014 International Conference on Self-Study of Teacher Education Practices. Studying Teacher Education, 13(1), 105-122. 
Nadin, S., \& Cassell, C. (2006). The use of a research diary as a tool for reflective practice: Some reflections from management research, Qualitative Research in Management \& Accountability, 3(3) 208-217.

Murphy, S., McGlynn-Stewart, M. \& Ghafour, F. (2014). Constructing Our Identities through a Writing Support Group: Bridging from Doctoral Students to Teacher Educator Researchers. Studying Teacher Education, 10(3), 239-254.

Murray, J., \& Male, T. (2005). Becoming a teacher educator: Evidence from the field. Teaching and Teacher Education, 21, 125-142.

Palmer, R., Hunt. A., Neal. M., \& Wuetherick. B. (2015). Mentoring, Undergraduate Research, and Identity Development: A Conceptual Review and Research Agenda. Mentoring \& Tutoring: Partnership in Learning. 23 (5), 411-426.

Pearson, M. \& Brew, A. (2002). Research training and supervision development. Studies in Higher Education, 27(2), 135-150.

Pinnegar, S., \& Hamilton, M.L. (2009). Self-Study of Practise as a Genre of Qualitative Research. Theory, Methodology and Practice. London: Springer.

Pinnegar, S., Hamilton, M.L., \& Fitzgerald, L. (2010). Guidance in being and becoming self-study of practice researchers. In. L. Erickson, J. Young, \& S. Pinnegar. (2010). Proceedings of the eighth international conference on self-studies of teacher education practices: Navigating the public and the private: Negotiating the diverse landscapes of teacher education (pp.203-206). Herstmonceaux Castle UK: Self-Study of Teacher Education Practices SIG.

Postholm, M. \& Skrøvset, S. (2013). The researcher reflecting on her own role during action research. Educational Action Research, 21(4), 506-518.

Price, D. \& Money, A. (2002). Alternative models for doctoral mentor organisation and research supervision, Mentoring and Tutoring, 10(2), 127-136. 
Reedy, K., \& Taylor-Dunlop, K. (2015). Mentor-Mentee Relationship in an Educational Leadership Doctoral Program at Lynn University. Journal for Leadership And Instruction, 14(1), 38-40.

Samaras, A. P. (2011). Self-study teacher research: Improving your practice through collaborative inquiry. Thousand Oaks, CA: Sage.

Sommers, N. \& L. Saltz. (2004). The novice as expert: Writing in the freshman year. College Communication and Composition, 56, 124-49.

Walkington, J. (2005). Becoming a teacher: Encouraging development of teacher identity through reflective practice. Asia-Pacific Journal of Teacher Education, 33(1), 3-64.

Wellington, J. (2010). More than a matter of cognition: An exploration of affective writing problems of post-graduate students and their possible solutions. Teaching in Higher Education, 15, 134-150.

Williams, J., Ritter, J.K., \& Bullock, S. M. (2012). Understanding the complexity of becoming a teacher educator: Experience, belonging, and practice within a professional learning community. Studying Teacher Education, 8 (3), 245-260.

Wisker, G. (2012). The Good Supervisor: Supervising Postgraduate and Undergraduate Research for Doctoral Theses and Dissemination (2 ${ }^{\text {nd }}$ ed.). UK: PALGRAVE MACMILLIAN.

Zeichner, K. (2007). Accumulating knowledge across self-studies in teacher education. Journal of Teacher Education, 58, 36-46.

Zerzan, J. T., Hess, R., Schur, E., Phillips, R. S., \& Rigotti, N. (2009). Making the most of mentors: a guide for mentees. Academic Medicine: Journal of The Association of American Medical Colleges, 84(1), 140-144. 